\title{
Pulsed Radiofrequency for Chronic Pain
}

\author{
David Byrd, MD, MPH and Sean Mackey, MD, PhD
}

\section{Introduction}

Pulsed radiofrequency (PRF) is a novel therapeutic modality with many potential applications in pain management. A variation of conventional continuous radiofrequency (CRF), which has been in use since the mid-1970s, PRF offers the advantage of pain control without the tissue destruction and painful sequelae associated with CRF. This theoretical benefit of PRF is especially alluring in cases of neuropathic pain in which CRF is relatively contraindicated.

\section{History of Radiofrequency for Chronic Pain}

Although Cosman and his associates built the first CRF lesion generator in the early 1950s, CRF was first used to treat pain in 1974 [1]. In the early years, technological constraints limited CRF therapy to cervical and lumbar facet disease. However, the introduction of the 22-gauge RF cannula in 1981 allowed clinicians to administer CRF in precise anatomical locations and to control lesion size [2]. Since that time, CRF has been used to treat a host of painful conditions ranging from lumbar radicular pain [3] to intercostal neuralgia [4] and cervicogenic headaches [5]. Unfortunately, a significant hindrance to the greater acceptance of CRF has been the risk of motor deficits and deafferentation syndrome.

PRF was developed, in part, as a less destructive alternative to CRF. The impetus to conduct research into PRF emerged from an Austrian conference in 1995; Ayrapetyan, a scientist from Armenia, proposed that the clinical effect of CRF might be secondary to magnetic field exposure rather than tissue destruction [6]. Subsequent theoretical work by Cosman showed that the magnetic field produced by CRF was most likely too weak to have a biological effect, but that the rapidly changing electrical field was perhaps significant enough to do so [7]. Later discussions by Cosman, Sluijter, and Rittman centered on the notion that PRF, in theory, was capable of delivering radiofrequency energy sufficient to modulate the electrical field, but insufficient to cause tissue thermocoagulation. Several months after the initial conference, Radionics engineered a prototype PRF generator. Sluijter used this machine in early 1996 to conduct preliminary clinical trials and wrote the first report of the clinical effects of PRF on dorsal root ganglia in 1998 [8].

\section{Mechanism of Action}

CRF uses high-frequency alternating current to induce coagulative necrosis in the target tissue. Tissue destruction occurs with probe temperatures between $60^{\circ}$ and $80^{\circ} \mathrm{C}$. Because tissue heating decreases rapidly with distance from the electrode tip, CRF lesions are well circumscribed, thus offering an advantage over chemical neurolysis. With CRF, the

\footnotetext{
Copyright @ 2008 by Current Medicine Group LLC

Corresponding author Stanford University, 780 Welch Road \#208, Palo Alto, CA 94304, USA. smackey@stanford.edu. Disclosures

No potential conflict of interest relevant to this article was reported.
} 
magnitude of tissue destruction is related to the temperature of the tissue, as well as the size of the electrode and duration of the procedure.

In contrast, PRF uses radiofrequency current in short $(20 \mathrm{~ms})$, high-voltage bursts; the "silent" phase ( $480 \mathrm{~ms}$ ) of PRF allows time for heat elimination, generally keeping the target tissue below $42^{\circ} \mathrm{C}$. Although conventional theory espouses the notion that PRF does not cause thermal lesions, Cosman and Cosman [9••] demonstrated that even PRF can produce bursts of heat within the range requisite for tissue destruction. The possibility of tissue destruction with PRF is substantiated by in vitro egg white studies using PRF electrodes at $60^{\circ} \mathrm{C}$ or higher [10]. However, histopathologic work in rat dorsal root ganglia and sciatic nerves using PRF electrodes at $42^{\circ} \mathrm{C}$ has shown that PRF causes only transient endoneurial edema; this in contrast with the wallerian degeneration effected by CRF at $80^{\circ} \mathrm{C}$ [11]. Similar studies in rabbit dorsal root ganglia corroborate the notion that PRF is orders of magnitude less disruptive of cellular morphology than CRF [12]. Therefore, it appears that any thermal damage from PRF is minimal and not the manner by which PRF exerts its clinical effect.

Pulsed radiofrequency (PRF), a technology related to continuous radiofrequency, is unique in that it provides pain relief without causing significant damage to nervous tissue. The mechanism by which PRF controls pain is unclear, but it may involve a temperature-independent pathway mediated by a rapidly changing electrical field. Although much anecdotal evidence exists in favor of PRF, there are few quality studies substantiating its utility.

Accordingly, the mechanism by which PRF causes pain relief in the absence of significant heat-induced tissue damage is debatable. The notion that the electrical fields generated by PRF can affect neuronal membranes is supported by neurophysiologic studies that demonstrate PRF changes synaptic signaling and causes electroporation [9••]. A popular theory is that the rapidly changing electric fields produced by PRF alter the transmission of pain signals via a pathway involving c-Fos, a so-called immediate early gene. This theory is substantiated in a study by van Zundert et al. [13॰], who demonstrated that $\mathrm{CRF}$ at $67^{\circ} \mathrm{C}$, $\mathrm{PRF}$ at $42^{\circ} \mathrm{C}$ for 120 seconds, or PRF at $42^{\circ} \mathrm{C}$ for 8 minutes performed on rat dorsal root ganglia all increased c-Fos expression in the dorsal horn, a response that was sustained as long as 7 days after treatment. These results not only indicate a mechanism of c-Fos activation that is independent of temperature, but also hint at the inhibition of excitatory $\mathrm{C}$ fibers and long-term depression as a viable therapeutic mechanism in PRF. Unfortunately, this study somewhat contradicts a previous study conducted by Higuchi et al. [14], who found increased c-Fos immunoreactivity in laminae I and II of the rat dorsal horn only in rats treated with PRF at $38^{\circ} \mathrm{C}$ and not in those treated with $\mathrm{CRF}$ at $38^{\circ} \mathrm{C}$ or sham. Therefore, Richebe et al. [15•] rightfully caution against embracing the theory of a c-Fosmediated pathway due to the paucity of consistent molecular evidence as well as the lack of controlled studies demonstrating the efficacy of PRF overall. It is also important to note that changes in c-Fos are associated with a number of cellular processes and that the upregulation of c-Fos observed with PRF may be unrelated to the mechanism by which PRF produces its therapeutic effect. In addition to c-Fos, activating transcription factor 3 (ATF3), an indicator of "cellular stress," is also increased with PRF; interestingly, this effect is seen only in small-diameter C and Ad fibers [16]. However, as is the case with c-Fos, the actual role of ATF3 remains unclear. 


\section{Clinical Applications}

There are few studies exploring the efficacy of PRF in treating pain. Additionally, most reports are retrospective in nature and involve only small patient cohorts. The bulk of PRF research has been conducted in patients with axial low back pain; however, in recent years, PRF has been studied in a wider range of conditions.

\section{Axial pain}

A retrospective study by Mikeladze et al. [17] of 114 patients with cervical or lumbar facet joint pain responsive to diagnostic medial branch blocks and subsequently treated with PRF at $42^{\circ} \mathrm{C}$ for 120 seconds found that 68 patients had significant pain relief (> 50\% pain reduction) that lasted an average of nearly 4 months. They did not find any correlation between treatment efficacy and previous surgery, sex, duration of pain, stimulation thresholds, or spinal level.

Similarly, Lindner et al. [18] performed a retrospective analysis of 48 patients with low back pain treated with PRF at $42^{\circ} \mathrm{C}$ for 120 seconds after reporting pain relief with one series of diagnostic medial branch blocks. The authors found a successful outcome (> 60\% improvement) at 4 months in 21 of 29 patients without a history of back surgery and 5 of 19 patients who had undergone surgery, demonstrating not only a significant PRF effect $(P<$ 0.0001 and 0.0036 , respectively) in each group, but also a significant difference in PRF efficacy between the groups $(P=0.0028)$.

Tekin et al. [19] conducted a randomized, double-blind, sham lesion study comparing the efficacy of PRF at $42^{\circ} \mathrm{C}$ for 120 seconds versus $\mathrm{CRF}$ at $80^{\circ} \mathrm{C}$ for 90 seconds in treating lumbar facet pain in 60 patients ( $n=20$ in each group) and found that both CRF and PRF were more effective than local anesthetic alone, but that the duration of pain relief with PRF was less prolonged than that seen with CRF. However, the authors admit that the major limitation to their study was the risk of false-positive blocks.

A somewhat different study was performed by Teixeira and Sluijter [20]; it included eight patients treated with intradiscal PRF who reported a history of axial low back pain presumed to be discogenic in origin, as determined by negative diagnostic medial branch blocks. There was a significant decrease in pain scores after 3 months $(P<0.0001)$. Three patients were subsequently lost to long-term follow-up, which ranged from 6 to 25 months, but four of five patients available for evaluation indicated that they were pain free. The authors used PRF for 20 minutes at $60 \mathrm{~V}$ with a mean tip temperature of $41^{\circ} \mathrm{C}$.

\section{Radicular pain}

Van Zundert et al. [21••] recently reported a double-blind, sham-controlled, randomized clinical trial of the effects of PRF of dorsal root ganglia in 23 patients with chronic cervical radicular pain. PRF was performed for 120 seconds. The sham intervention involved placement of radiofrequency cannulas as well as sensory and motor testing, but no passing of RF current. At 3 months, the PRF group demonstrated significant benefit in both global perceived effect and visual analogue scale (VAS) measures $(P=0.03$ and $P=0.02$, respectively). No significant difference was noted between the groups at 3 months with respect to pain medication reduction, the third outcome measure; this measure reached statistical significance at 6 months. The authors conclude that PRF appears to provide pain relief in carefully selected patients with cervical radicular pain, but that this claim needs to be investigated in larger study populations. 


\section{Facial pain}

Van Zundert et al. [22] reported results from their study of five patients with idiopathic trigeminal neuralgia treated with PRF at $42^{\circ} \mathrm{C}$ for 120 seconds. Three of five patients demonstrated complete pain relief at long-term follow-up, ranging from 10 to 20 months. One patient had $90 \%$ pain relief at 22 months. The final patient indicated $75 \%$ pain relief at 1 month but eventually elected to undergo microvascular decompression.

Navani et al. [23] reported a single case of PRF of the greater occipital nerve for treatment of occipital neuralgia. The patient, a 62-year-old woman, had a 42-year history of left suboccipital pain. After a positive response to two diagnostic blocks, three rounds of PRF at $42^{\circ} \mathrm{C}$ for 120 seconds were performed on the medial branches of the $\mathrm{C} 1$ and $\mathrm{C} 2$ dorsal rami. At a 4-month follow-up, the patient had $60 \%$ to $70 \%$ pain relief and elected to undergo further PRF, which provided an additional 5 months of relief.

\section{Inguinal pain and orchialgia}

PRF has also shown some utility in treating inguinal pain. Rozen and Ahn [24] reported a case series of five patients with chronic ilioinguinal neuralgia after inguinal herniorrhaphy. After a positive response to selective nerve root blocks, each patient was treated with PRF at $42^{\circ} \mathrm{C}$ for 120 seconds at the T12, L1, and L2 sensory ganglia. Four of the five patients demonstrated significant pain relief at 4 and 9 months. These data are similar to those reported by other pain management practitioners [25].

In addition, Cohen and Foster [26] reported three cases of patients with groin pain or orchialgia treated with PRF. Each patient underwent PRF of the appropriate nerve (ilioinguinal or genitofemoral) at $42^{\circ} \mathrm{C}$ for 120 seconds subsequent to receiving diagnostic nerve blocks. All three patients had complete resolution of their pain complaints at 6 months.

\section{Miscellaneous pain syndromes}

Vallejo et al. [27] reported a prospective case series of 22 patients with sacroiliac joint pain treated with PRF who failed to respond to sacroiliac joint injections with steroid and local anesthetic. PRF at $42^{\circ} \mathrm{C}$ for 120 seconds was performed twice at the L4 and L5 medial branches as well as the S1 and S2 lateral branches. VAS scores were significantly decreased $(P<0.0001)$ at 6 months. Physical well-being and functional well-being measures also showed significantly reduced scores at 6 months (both $P$ values $<0.0001$ ).

A case report presented by Shah and Racz [28] indicated excellent pain relief with PRF of the suprascapular nerve in a patient with glenohumeral osteoarthritis and adhesive capsulitis. PRF was performed at $42^{\circ} \mathrm{C}$ for three cycles of 120 seconds. Each PRF session afforded the patient with 4 to 5 months of pain relief and improvement in shoulder function.

A retrospective analysis conducted by Cohen et al. [29] of 46 patients with post-surgical thoracic pain found that PRF of the dorsal root ganglion was more beneficial than pharmacologic treatment or PRF of the intercostal nerves. Success was defined as more than $50 \%$ pain relief at 6 weeks and 3 months, as well as positive responses to satisfaction and functional improvement questionnaires. No differences between the groups were statistically significant at 6 weeks. At 3 months, however, the group treated with PRF of the dorsal root ganglion had significantly better pain relief than the group treated with PRF of the intercostal nerves $(P=0.01)$. When compared with the medical management group, the dorsal root ganglion cohort demonstrated a pain relief advantage that approached significance $(P=0.06)$. The authors emphasized the need for prospective studies to confirm their findings. 
Shabat et al. [30] performed a prospective cohort study of 28 patients with "neuropathic spinal pain" treated with PRF. PRF was administered at the dorsal root ganglia using electrodes at $42^{\circ} \mathrm{C}$ for 120 seconds. At 1-month follow-up, 24 of 28 (86\%) patients reported complete, moderate, or good pain relief. At 3, 6, and 12 months, some degree of pain relief was reported in 23 of $28(82 \%), 20$ of 28 (71\%), and 19 of 28 (68\%) patients, respectively. The authors did not conduct a statistical analysis of their data.

\section{Discussion}

PRF has several characteristics that make it, in theory, a better therapeutic option than CRF. In addition to lacking the tissue destruction requisite with CRF, PRF also offers broader applicability to pathological conditions such as neuropathic pain. PRF is an especially favorable intervention in these cases because the inciting event is thought to be a nerve injury, and inflicting further tissue damage is counterintuitive. PRF also appears to be a relatively safe procedure. Unlike $\mathrm{CRF}$, which is associated with neuritis-like reactions, motor deficits, and the risk of deafferentation pain, PRF seems to have few side effects; indeed, we failed to find any reports of adverse reactions secondary to PRF. In addition, $\mathrm{PRF}$ also may have a number of potential financial advantages over CRF [31].

Despite the appeal of PRF, there remain a number of obstacles preventing its more widespread inclusion into the armamentarium of pain management procedures. A formidable problem is the relative lack of randomized controlled studies substantiating the efficacy of PRF. The recent double-blind study by Van Zundert et al. [21 ••] is a significant advancement in this regard. However, their report, like others, is limited by a relatively small sample size, bringing into question the validity of any conclusions. As noted by Gallagher [32] and others [33••,34], double-blind controlled studies are intrinsically difficult in the pain population due to the natural history of pain syndromes and the ethical problems associated with sham trials. Such studies are also troublesome due to the etiological heterogeneity of pain disorders [35].

Characterizing the mechanism by which PRF exerts its biological effect also is a substantial challenge. Cosman and Cosman's [9••] seminal report of the electrical and thermal effects of the tissue adjacent to radiofrequency electrodes lends strong credence to the notion that the beneficial effects of PRF are not secondary to thermal injury. Despite some investigation, the role of immediate early genes and other biochemical factors continues to be elusive. Additional studies similar to those performed by Higuchi et al. [14] are indicated.

\section{Conclusions}

The emergence of PRF technology represents a promising step toward treating complicated pain conditions. As the evidence in support of PRF accumulates, it is likely that its potential to be applied more broadly will also increase. Further evaluation, however, will determine whether PRF falls by the wayside as another "ballyhooed intervention" [32] or persists as a legitimate therapeutic tool.

\section{References and Recommended Reading}

Papers of particular interest, published recently, have been highlighted as:

- Of importance

•• Of major importance 
1. Uematsu S, Udrarhelyi GB, Benson DW, et al. Percutaneous radiofrequency rhizotomy. Surg Neurol 1974;2:319-325. [PubMed: 4853577]

2. Ahadian FM. Pulsed radiofrequency neurotomy: advances in pain medicine. Curr Pain Headache Rep 2004;8:34-40. [PubMed: 14731381]

3. Guerts JWM, van Wijk RM, Wynne HJ, et al. Radio-frequency lesioning of dorsal root ganglia for chronic lumbosacral radicular pain: a randomised, double blind, controlled study. Lancet 2003;361:21-26. [PubMed: 12517462]

4. van Kleef M, Spaans F. The effects of producing a radiofrequency lesion adjacent to the dorsal root ganglion in patients with thoracic segmental pain by radiofrequency percutaneous partial rhizotomy. Clin J Pain 1995;11:325-332. [PubMed: 8788580]

5. van Suijlekom JA, van Kleef M, Barendse G. Radio-frequency cervical zygapophyseal joint neurotomy for cervicogenic headache. A prospective study in 15 patients. Funct Neurol 1998;13:297-303. [PubMed: 9934574]

6. Sluijter ME. Pulsed radiofrequency. Anesthesiology 2005;103:1313-1314. [PubMed: 16306748]

7. Cosman ER. A comment on the history of the pulsed radiofrequency technique for pain therapy. Anesthesiology 2005;103:1312-1314. [PubMed: 16306746]

8. Sluijter ME, Cosman E, Rittman W, et al. The effect of pulsed radiofrequency fields applied to the dorsal root ganglion. Pain Clin 1998;11:109-117.

9••. Cosman ER Jr, Cosman ER Sr. Electric and thermal field effects in tissue around radiofrequency electrodes. Pain Med 2005;6:405-424. [PubMed: 16336478] [An important study detailing the physics behind PRF.]

10. Heavner JE, Boswell MV, Racz GB. A comparison of pulsed radiofrequency and continuous radiofrequency on thermocoagulation of egg white in vitro. Pain Physician 2006;9:135-137. [PubMed: 16703974]

11. Podhajsky RJ, Sekiguchi Y, Kikuchi S, et al. The histologic effects of pulsed and continuous radiofrequency lesions at 42 degrees $C$ to rat dorsal root ganglion and sciatic nerve. Spine 2005;30:1008-1013. [PubMed: 15864151]

12. Erdine S, Yucel A, Cimen A, et al. Effects of pulsed versus conventional radiofrequency current on rabbit dorsal root ganglion morphology. Eur J Pain 2005;9:251-256. [PubMed: 15862474]

13•. van Zundert J, de Louw AJ, Joosten EA, et al. Pulsed and continuous radiofrequency current adjacent to the cervical dorsal root ganglion of the rat induces late cellular activity in the dorsal horn. Anesthesiology 2005;102:125-131. [PubMed: 15618796] [An early study of the relationship between PRF and c-Fos.]

14. Higuchi Y, Nashold BS, Sluijter M, et al. Exposure of the dorsal root ganglion in rats to pulsed radiofrequency currents activates dorsal horn lamina I and II neurons. Neurosurgery 2002;50:850855. [PubMed: 11904038]

15•. Richebe P, Rathmell JP, Brennan TJ. Immediate early genes after pulsed radiofrequency treatment: neurobiology in need of clinical trials. Anesthesiology 2005;102:1-3. [PubMed: 15618777] [A cautionary editorial regarding PRF.]

16. Hamann W, Abou-Sherif S, Thompson S, et al. Pulsed radiofrequency applied to dorsal root ganglia causes a selective increase in ATF3 in small neurons. Eur J Pain 2006;10:171-176. [PubMed: 16310722]

17. Mikeladze G, Espinal R, Finnegan R, et al. Pulsed radiofrequency application in treatment of chronic zygapophyseal joint pain. Spine J 2003;3:360-362. [PubMed: 14588947]

18. Lindner R, Sluijter ME, Schleinzer W. Pulsed radiofrequency treatment of the lumbar medial branch for facet pain: a retrospective analysis. Pain Med 2006;7:435-439. [PubMed: 17014603]

19. Tekin I, Mirzai H, Ok G, et al. A comparison of conventional and pulsed radiofrequency denervation in the treatment of chronic facet joint pain. Clin J Pain 2007;23:524-529. [PubMed: 17575493]

20. Teixeira A, Sluijter ME. Intradiscal high-voltage, long-duration pulsed radiofrequency for discogenic pain: a preliminary report. Pain Med 2006;7:424-428. [PubMed: 17014601]

21••. van Zundert J, Patijn J, Kessels A, et al. Pulsed radiofrequency adjacent to the cervical dorsal root ganglion in chronic cervical radicular pain: a double blind sham controlled randomized 
clinical trial. Pain 2007;127:173-182. [PubMed: 17055165] [One of the few controlled PRF studies.]

22. van Zundert J, Brabant S, van de Kelft E, et al. Pulsed radiofrequency treatment of the Gasserian ganglion in patients with idiopathic trigeminal neuralgia. Pain 2003;104:449-452. [PubMed: 12927617]

23. Navani A, Mahajan G, Kreis P, et al. A case of pulsed radiofrequency lesioning for occipital neuralgia. Pain Med 2006;7:453-456. [PubMed: 17014606]

24. Rozen D, Ahn J. Pulsed radiofrequency for the treatment of ilioinguinal neuralgia after inguinal herniorrhaphy. Mt Sinai J Med 2006;73:716-718. [PubMed: 16878278]

25. Martin DC. Pulsed radiofrequency application for inguinal herniorraphy pain. Pain Physician 2006;9:271. [PubMed: 16886040]

26. Cohen SP, Foster A. Pulsed radiofrequency as a treatment for groin pain and orchialgia. Urology 2003;61:645. [PubMed: 12639676]

27. Vallejo R, Benyamin RM, Kramer J, et al. Pulsed radiofrequency denervation for the treatment of sacroiliac joint syndrome. Pain Med 2006;7:429-434. [PubMed: 17014602]

28. Shah RV, Racz GB. Pulsed mode radiofrequency lesioning of the suprascapular nerve for the treatment of chronic shoulder pain. Pain Physician 2003;6:503-506. [PubMed: 16871304]

29. Cohen SP, Sireci A, Wu CL, et al. Pulsed radiofrequency of the dorsal root ganglia is superior to pharmacotherapy or pulsed radiofrequency of the intercostal nerves in the treatment of chronic postsurgical thoracic pain. Pain Physician 2006;9:227-235. [PubMed: 16886031]

30. Shabat S, Pevsner Y, Folman Y, et al. Pulsed radiofrequency in the treatment of patients with chronic neuropathic spinal pain. Minim Invasive Neurosurg 2006;49:147-149. [PubMed: 16921454]

31. Bogduk N. Pulsed radiofrequency. Pain Med 2006;7:396-407. [PubMed: 17014598]

32. Gallagher RM. Pulsed radiofrequency treatment: what is the evidence of its effectiveness and should it be used in clinical practice? Pain Med 2006;7:408-410. [PubMed: 17014599]

33••. Cahana A, Van Zundert J, Macrea L, et al. Pulsed radiofrequency: current clinical and biological literature available. Pain Med 2006;7:411-423. [PubMed: 17014600] [An excellent review of the PRF literature.]

34. Cahana A. Pulsed radiofrequency: a neurobiologic and clinical reality. Anesthesiology 2005;103:1311, 1313-1314. [PubMed: 16306745]

35. Jensen TS. Pulsed radiofrequency: a novel treatment for chronic cervical radicular pain? Pain 2007;127:3-4. [PubMed: 16971045] 